\title{
Resveratrol rescues TNF- $\alpha$-induced inhibition of osteogenesis in human periodontal ligament stem cells via the ERK1/2 pathway
}

\author{
JIAKAN YUAN ${ }^{1-3}$, XUXIA WANG ${ }^{1,4}$, DAN MA $^{1,2}$, HUI GAO $^{1,5}$, DEHUA ZHENG $^{1,2}$ and JUN ZHANG ${ }^{1,2}$ \\ ${ }^{1}$ Shandong Provincial Key Laboratory of Oral Tissue Regeneration \& Shandong Engineering Laboratory for Dental Materials \\ and Oral Tissue Regeneration; ${ }^{2}$ Department of Orthodontics, School of Stomatology, Shandong University, \\ Jinan, Shandong 250012; ${ }^{3}$ Department of Stomatology, Heze Municipal Hospital, Heze, Shandong 274000; \\ ${ }^{4}$ Department of Oral and Maxillofacial Surgery, School of Stomatology, Shandong University, Jinan, Shandong 250012; \\ ${ }^{5}$ Department of Stomatology, Weifang People's Hospital, Weifang, Shandong 261041, P.R. China
}

Received April 11, 2019; Accepted January 8, 2020

DOI: $10.3892 / \mathrm{mmr} .2020 .11021$

\begin{abstract}
Periodontitis is a common inflammatory disorder affecting the tissues surrounding the teeth, which can lead to the destruction of periodontal tissue and tooth loss. Resveratrol, a natural phytoalexin, exerts multiple biological effects. For example, its anti-inflammatory activity has been widely studied for the treatment of inflammatory bowel disease for a number of years. However, its effect on bone repair and new bone formation in an inflammatory microenvironment is not well understood. Accordingly, the effect of resveratrol on inflammation-affected human periodontal ligament stem cells (hPDLSCs) requires further investigation. In the present study, the effect of tumor necrosis factor- $\alpha$ (TNF- $\alpha$ ), resveratrol, or the combination of both on the osteogenic differentiation of hPDLSCs, as well as the underlying mechanisms involved, were investigated. Cell Counting Kit-8 assay, alkaline phosphatase staining, Alizarin red staining, Oil Red O staining, reverse transcription-quantitative PCR and western blotting were used in the present study. It was demonstrated that resveratrol enhanced hPDLSC osteogenesis and reversed the inhibitory effects of TNF- $\alpha$ on this process. Further mechanistic studies indicated that resveratrol exerted anti-inflammatory activity by activating the ERK1/2 pathway, decreasing the secretion of interleukin (IL)- 6 and IL-8 induced by TNF- $\alpha$, and enhancing hPDLSCs osteogenesis. The present study suggested that
\end{abstract}

Correspondence to: Professor Jun Zhang, Department of Orthodontics, School of Stomatology, Shandong University, 44-1 Wenhua Xi Road, Jinan, Shandong 250012, P.R. China E-mail: zhangj@sdu.edu.cn

Abbreviations: ALP, alkaline phosphatase; BMSCs, bone marrow-derived mesenchymal stem cells; hPDLSCs, human periodontal ligament stem cells; MSCs, mesenchymal stem cells; TNF- $\alpha$, tumor necrosis factor- $\alpha$

Key words: resveratrol, TNF- $\alpha$, osteogenesis, hPDLSC, periodontitis resveratrol may be a novel and promising therapeutic choice for periodontitis.

\section{Introduction}

Conventional therapies have succeeded in controlling periodontal inflammation but cannot restore the damage to periodontal tissues (1). In previous years, tissue engineering technologies have offered a promising approach for complete periodontal tissue regeneration (2). A previous study also indicated that human periodontal ligament stem cells (hPDLSCs) possess multi-potency and can differentiate into cementoblast-like cells, adipocytes and collagen-forming cells (3). Thus, hPDLSCs are a promising stem cell population for complete periodontal tissue regeneration.

Decreased estrogen levels are the primary cause of osteoporosis in menopausal women. Accordingly, estrogen can be used to prevent postmenopausal osteoporosis (4). After bone maturation, this tissue is constantly remodeled throughout adult life (5). Estrogen plays an important role in maintaining the balance between bone resorption and bone formation (6). Phytoestrogens are a group of naturally existing compounds in plants with mammalian estrogen-like activity (7). Resveratrol, a well-known phytoestrogen, is a phenolic compound that exists in red wines, peanuts, mulberries and the berry skins of the majority of grape cultivars (8). Previous studies have shown that resveratrol has estrogenic activity $(9,10)$. It also has several biological effects including anticancer activity (11), cardiovascular protection (12) and anti-inflammatory properties (13).

Furthermore, the bone protective activities of resveratrol have attracted extensive interest $(14,15)$. One study has demonstrated that resveratrol promotes the proliferation and differentiation of osteoblastic MC3T3-E1 cells in vitro (16). Dai et al (17) reported that resveratrol stimulates human mesenchymal stem cell (MSC) proliferation and osteoblast differentiation via ERK-dependent ERK1/2 activation. Previously, resveratol was also found to enhance the osteogenesis of human MSCs by upregulating Runt-related transcription factor 2 (Runx2) gene expression via the NAD-dependent protein deacetylase sirtuin-1 (SIRT1)/forkhead box protein $\mathrm{O} 3$ (FOXO3A) axis (18). 
Tumor necrosis factor- $\alpha(\mathrm{TNF}-\alpha)$ plays a critical role in inflammation, which can be rapidly secreted by macrophages and T lymphocytes (19). Accordingly, it is involved in several inflammatory bone diseases such as rheumatoid arthritis and periodontitis $(20,21)$. This cytokine can also inhibit the osteogenic differentiation of MSCs. However, although it has been hypothesized that resveratrol could positively regulate the osteoblastic differentiation of hPDLSCs in an inflammatory microenvironment induced by $\mathrm{TNF}-\alpha$, this has previously not been elucidated.

In the present study, the effect of resveratrol and TNF- $\alpha$ on hPDLSC proliferation and osteoblast differentiation was investigated.

\section{Materials and methods}

Tissue collection and cell culture. hPDLSCs were collected from wisdom teeth and premolars extracted from 20 individuals aged 12-20 years. Volunteers included 15 males and five females with a mean age of 14 years (age, 12-20 years). The recruitment was carried out between June and September 2017. All procedures were performed at the Department of Oral \& Maxillofacial Surgery (School of Stomatology, Shandong University), and written informed consent was obtained from each participant and the legal guardians of all children. The extracted teeth were placed in $\alpha$-Minimal Essential Medium ( $\alpha$-MEM; Gibco; Thermo Fisher Scientific, Inc.) supplemented with penicillin $(400 \mathrm{U} / \mathrm{ml})$ and streptomycin $(400 \mathrm{mg} / \mathrm{ml})$ on ice and were delivered to the Shandong Provincial Key Laboratory of Oral Tissue Regeneration immediately. Periodontal membranes were scraped from the middle third of the healthy non-carious root surface and cut into $1.0 \mathrm{~mm}^{3}$ fragments with an aseptic scalpel, as previously described (22). The fragments were tiled on the bottom of a culture bottle and cultured in $\alpha$-MEM supplemented with 20\% FBS (Gibco; Thermo Fisher Scientific, Inc.), $100 \mathrm{U} / \mathrm{ml}$ penicillin $\mathrm{G}$ and $100 \mu \mathrm{g} / \mathrm{ml}$ streptomycin. The culture bottle was turned over $4 \mathrm{~h}$ later and incubated at $37^{\circ} \mathrm{C}$ with $5 \% \mathrm{CO}_{2}$. When the cells grew to $80 \%$ confluence, cells were digested with $0.25 \%$ trypsin. Single cell colonies were subcultured as previously described (23), and cells at passages 3-5 were used for the following experiments. hPDLSC morphology was assessed using an inverted microscope at a magnification of $\mathrm{x} 100$ and $\mathrm{x} 200$.

Cell proliferation assay. The effect of resveratrol on hPDLSC viability was investigated using a Cell Counting Kit-8 (CCK-8) assay (Dojindo Molecular Technologies, Inc.), according to the manufacturer's instructions. hPDLSCs were seeded into 96-well plates at a density of $3 \times 10^{3}$ per well. Cells were then cultured with complete medium ( $\alpha$-MEM containing $10 \%$ FBS) for $24 \mathrm{~h}$ at $37^{\circ} \mathrm{C}$. After the cells attached to the flask, the culture medium was changed to complete medium containing TNF- $\alpha$ (1,5 and 10 ng/ml; PeproTech) and/or Resveratrol (0.1,1 and $10 \mu \mathrm{M}$; Sigma-Aldrich; Merck KGaA). The medium was subsequently changed every three days. On day one, three and five, the culture medium in each well was substituted for $10 \%$ CCK-8 reagent (100 $\mu \mathrm{l})$. Next, the 96 -well plate was incubated for $2 \mathrm{~h}$ in an incubator at $37^{\circ} \mathrm{C}$. Absorbance was recorded at a wavelength of $450 \mathrm{~nm}$ using a SPECTROstar
Nano ultraviolet spectrophotometer (Spectro Analytical Instruments $\mathrm{GmbH}$ ).

Flow cytometry. To analyze cell surface marker proteins, hPDLSCs at passage 3 were collected using $0.25 \%$ trypsin and resuspended in PBS. In brief, $1 \times 10^{6}$ cells in suspension were incubated with fluorescent dye-conjugated monoclonal antibodies at $4^{\circ} \mathrm{C}$ for $20 \mathrm{~min}$ in the dark, washed three times using PBS (Corning, Inc.), and then analyzed using a flow cytometer and FlowJo ${ }^{\circledR}$ software (version 10.5.2; BD Biosciences) was used to analyze the data. The antibodies used for these experiments were CD34-PE (cat. no. 12-0349-41; $5 \mu \mathrm{l} /$ test; eBioscience; Thermo Fisher Scientific, Inc.), CD44-PE (cat. no. 12-0441-81; $0.125 \mu \mathrm{g} /$ test; Affymetrix; Thermo Fisher Scientific, Inc.), CD90Thy-1-PE (cat. no. 15-0909-42; $5 \mu \mathrm{l} /$ test; Affymetrix; Thermo Fisher Scientific, Inc.), CD105-APC (cat. no. 17-1057-42; $5 \mu$ 1/test; Affymetrix; Thermo Fisher Scientific, Inc.) and CD45-PE (cat. no. 12-0451-82; $0.125 \mu \mathrm{g} /$ test; eBioscience; Thermo Fisher Scientific, Inc.).

Alkaline phosphatase (ALP) staining and activity assay. ALP is an osteogenic marker expressed at the early stage of osteogenic differentiation (24). For ALP staining, hPDLSCs were cultured in the osteogenic induction medium (Cyagen Science $\&$ Technology Co., Ltd.) for 14 days. The cells were then washed with PBS and fixed with $4 \%$ paraformaldehyde at $4{ }^{\circ} \mathrm{C}$ for 30 min. A 5-bromo-4-chloro-3-indolyl phosphate (BCIP)/nitro blue tetrazolium (NBT) ALP staining kit (Beyotime Institute of Biotechnology) was used for ALP staining according to manufacturer's instructions, and the stained samples were observed with an inverted fluorescence microscope (x100). For ALP activity assays, cells were seeded in 6-well plates at the density of $2 \times 10^{5}$ per well. After 14 days of incubation, hPDLSCs were washed with PBS and scraped into $100 \mu 1$ of radioimmunoprecipitation assay buffer (Beijing Solarbio Science \& Technology Co., Ltd.) containing $1 \%$ phenylmethylsulphonyl fluoride (Beijing Solarbio Science \& Technology Co., Ltd.). The collected cells were sonicated at $20 \mathrm{KHz}$ for $15 \mathrm{sec}$ on ice, and the lysates were centrifuged at $12,000 \mathrm{x} \mathrm{g}$ for $15 \mathrm{~min}$ at $4^{\circ} \mathrm{C}$. Then, ALP activity in each sample was assayed using the ALP assay kit (Nanjing Jiancheng Bioengineering Institute) according to manufacturer's instructions. Briefly, $50 \mu \mathrm{l}$ of buffer solution, $30 \mu \mathrm{l}$ of supernatant, and $50 \mu \mathrm{l}$ of matrix liquid were added to each well of a 96 -well plate and mixed. The plate was then incubated at $37^{\circ} \mathrm{C}$ for $15 \mathrm{~min}$. The absorbance was measured at $520 \mathrm{~nm}$ after $150 \mu \mathrm{l}$ of coloration solution was added to each well. ALP activity was normalized to total protein amounts which determined by bicinchoninic acid assay kit (Beijing Solarbio Science \& Technology Co., Ltd), according to manufacturer's instructions.

Alizarin red staining and calcium content assay. hPDLSCs were seeded in 6-well plates at $1.5 \times 10^{5}$ cells per well and cultured for 21 days in osteogenic medium with or without resveratrol treatment, as indicated in the experiments (Resveratrol $1 \mu \mathrm{M}$; TNF- $\alpha 10 \mathrm{ng} / \mathrm{ml}$ ). After treatment, the cells were washed three times with PBS and fixed with $4 \%$ paraformaldehyde at room temperature for $30 \mathrm{~min}$. After three washes with deionized water, hPDLSCs were stained with $1 \%$ alizarin red $(\mathrm{pH} \mathrm{4.2,}$ Beijing Solarbio Science \& Technology Co., Ltd.) for $10 \mathrm{~min}$ 
at room temperature. Then, $600 \mu 1$ of $10 \%(\mathrm{w} / \mathrm{v})$ cetylpyridinium chloride (Sigma-Aldrich; Merck KGaA) was added to the stained wells and the absorbance of the extracted dye was assayed at $562 \mathrm{~nm}$ using a spectrophotometer (SPECTROstar Nano).

Oil Red $O$ staining. For adipogenic induction, hPDLSCs $\left(1 \times 10^{4} /\right.$ well $)$ were seeded in a 24 -well plate. Then, the cells were exposed to adipogenic induction medium that included $\alpha$-MEM containing $10 \% \mathrm{FBS}, 0.2 \mathrm{mmol} / 1$ indomethacin (Sigma-Aldrich; Merck KGaA), $2 \mu \mathrm{M}$ dexamethasone (Beijing Solarbio Science \& Technology Co., Ltd.), 0.01 g/l insulin (Sigma-Aldrich; Merck KGaA) and $0.5 \mathrm{mmol} / 1$ isobutyl-meth-ylxanthine (Sigma-Aldrich; Merck KGaA). Following 4 weeks of induction, the lipid droplets were stained with Oil Red O (cyagen Biosciences, Suzhou, china) for $30 \mathrm{~min}$ at room temperature, and then observed with an inverted fluorescent microscope (Olympus Corporation) at a magnification of $x 400$.

Reverse transcription-quantitative PCR (RT-qPCR). hPDLSCs ( $2 \times 10^{5} /$ well) were seeded in 6-well plates. Total RNA was isolated after seven, 14 and 21 days of culture using TRIzol ${ }^{\circledR}$ (Invitrogen; Thermo Fisher Scientific, Inc.), according to the manufacturer's protocol. cDNA was synthesized from $1.0 \mu \mathrm{g}$ of total RNA using RevertAid First Strand cDNA Synthesis kit (Invitrogen; Thermo Fisher Scientific, Inc.) according to the manufacturer's instructions. qPCR was performed utilizing the Roche Light Cycler 480 with a $10 \mu \mathrm{l}$ reaction volume. The reaction system contained $5 \mu \mathrm{l} \mathrm{SYBR}{ }^{\circledR}$ Premix Ex Taq ${ }^{\mathrm{TM}}$ (Takara Bio, Inc.), $1 \mu \mathrm{l}$ cDNA, $0.2 \mu \mathrm{l}$ of each primer and 3.6 $\mu \mathrm{l}$ RNase-free $\mathrm{H}_{2} \mathrm{O}$, following the manufacturer's protocol. The thermal cycling conditions were as follows: Incubation at $95^{\circ} \mathrm{C}$ for $15 \mathrm{~min}, 45$ cycles of denaturation at $95^{\circ} \mathrm{C}$ for $5 \mathrm{sec}$ and annealing at $60^{\circ} \mathrm{C}$ for $35 \mathrm{sec}$, and a final extension at $72^{\circ} \mathrm{C}$ for $3 \mathrm{~min}$. The relative expression levels of $A L P$, Runx2, Interleukin (IL)- 6 and $I L-8$ were normalized to those of $G A P D H$. The following primers were used for RT-qPCR: GAPDH forward, 5'-GCACCGTCAAGGCTGAGA AC-3' and reverse, 5'-TGGTGAAGACGCCAGTGGA-3'; Runx2 forward, 5'-TCCACACCATTAGGGACCATC-3' and reverse, 5'-TGCTAATGCTTCGTGTTTCCA-3'; ALP forward, 5'-ATG GGATGGGTGTCTCCACA-3' and reverse, 5'-CCACGAAGG GGAACTTGTC-3'; IL-6 forward, 5'-ATAACCACCCCTGAC CCAAC-3' and reverse, 5'-CCCATGCTACATTTGCCGAA-3' and IL-8 forward, 5'-TCAGAGACAGCAGAGCACAC-3' and reverse, 5'-GGCAAAACTGCACCTTCACA-3'. The relative gene expression was calculated using the $2^{-\Delta \Delta \mathrm{Cq}}$ method (25), normalizing to GAPDH levels.

Western blotting. To measure protein levels, hPDLSCs were cultured in a 6 -well plate at a density of $2 \times 10^{5}$ per well for further treatment. Cells were cultured with osteogenic induction medium, osteogenic induction medium + Resveratrol $1 \mu \mathrm{mol} / \mathrm{l}$, osteogenic induction medium $+\mathrm{TNF}-\alpha 10 \mathrm{ng} / \mathrm{ml}$ or osteogenic induction medium + Resveratrol $1 \mu \mathrm{mol} / 1+\mathrm{TNF}-\alpha$ $10 \mathrm{ng} / \mathrm{ml}$, respectively. After 3 weeks of osteogenic induction, cells were rinsed three times with PBS before being collected with RIPA buffer (Beyotime Institute of Biotechnology) for 30 min on ice. Then, the protein concentrations were measured using a bicinchoninic acid assay (Beijing Solarbio Science \&
Technology co., Ltd.). Next, $10 \mu \mathrm{g}$ protein samples were separated using $10 \%$ SDS-PAGE gels and then transferred to PVDF membranes (Bio-Rad Laboratories, Inc.). The membranes were blocked with $5 \%$ non-fat milk for $1 \mathrm{~h}$ at room temperature, incubated with primary antibodies overnight at $4^{\circ} \mathrm{C}$, and then incubated with horseradish peroxidase (HRP)-conjugated anti-rabbit or anti-mouse IgG (cat. no. SA00001-2 and SA00011; both at 1:10,000 dilution; Proteintech Group, Inc.) for $1 \mathrm{~h}$ at room temperature. The bands were detected using the chemiluminescent HRP substrate (EMD Millipore) and scanned utilizing an Amersham Imager 600 (GE Healthcare Life Sciences). Semi-quantitative analysis of western blotting was performed with the Image J software (version 1.47; National Institutes of Health). GAPDH is used as reference protein in the study. The primary antibodies and dilution ratios were as follows: Rabbit anti-human ALP (cat. no. ab108337; 1:20,000; Abcam), rabbit anti-human GAPDH (cat. no. cst2118; 1:1,000; Cell Signaling Technology, Ltd.), rabbit anti-human Runx2 (cat. no. cst12556s; 1:1,000: Cell Signaling Technology, Ltd.), rabbit anti-human ERK1/2 (cat. no. cst4695; 1:1,000; Cell Signaling Technology, Ltd.), and rabbit anti-phosphorylated (p)-ERK1/2 (cat. no. cst4370; 1:1,000; Cell Signaling Technology, Ltd.).

ERK1/2 pathway activation and inhibition studies. To activate the ERK1/2 pathway, hPDLSCs $\left(2 \times 10^{5}\right.$ per well) were seeded in a 6 -well plate. The cells were cultured with $\alpha$-MEM containing $10 \% \mathrm{FBS}$ at $37^{\circ} \mathrm{C}$ for $24 \mathrm{~h}$. Then, the cells were maintained in $\alpha$-MEM containing $0.5 \%$ FBS for $48 \mathrm{~h}$ to synchronize the cells and reduce basal ERK1/2 activity (26). PD98059 (10 $\left.{ }^{-5} \mathrm{~mol} / \mathrm{l}\right)$, an inhibitor of the upstream mitogen-activated protein kinase (MAPK)-ERK 1 pathway (27), was added to the serum-free culture media $1 \mathrm{~h}$ prior to the application of resveratrol, to assess its effect on ERK1/2 pathway activity. Then, the lysates were collected for western blotting.

ELISA. To further clarify the effect of resveratrol $(1 \mu \mathrm{mol} / \mathrm{l})$ or resveratrol $(1 \mu \mathrm{mol} / \mathrm{l})$ plus PD98059 $\left(10^{-5} \mathrm{~mol} / \mathrm{l}\right)$ on TNF- $\alpha$-induced inflammatory cytokine production, after TNF- $\alpha$ treatment, the levels of secreted IL- 6 and IL- 8 within the conditioned medium were measured using an ELISA kit (IL-6 cat. no. 430507 and IL-8 cat. no. 431507; BioLegend, Inc.) according to the manufacturer's instructions. The optical density values were measured using a microplate reader at 450 and $570 \mathrm{~nm}$, and values at $570 \mathrm{~nm}$ were subtracted from the absorbance at $450 \mathrm{~nm}$ for subsequent data analysis.

Statistical analysis. All experiments were performed in triplicate. The significance of differences among the groups was assessed by one-way ANOVA followed by Tukey's post-hoc test. The significance of differences among multiple groups at different time points was assessed by two-way ANOVA followed by Tukey's post-hoc test. Data were analyzed using GraphPad Prism (version 6; GraphPad Software, Inc.). All data are presented as the mean \pm standard deviation (SD). $\mathrm{P}<0.05$ was considered to indicate a statistically significant difference.

\section{Results}

Characterization of hPDLSCs. The characteristics of hPDLSCs were confirmed by examining their morphology, 


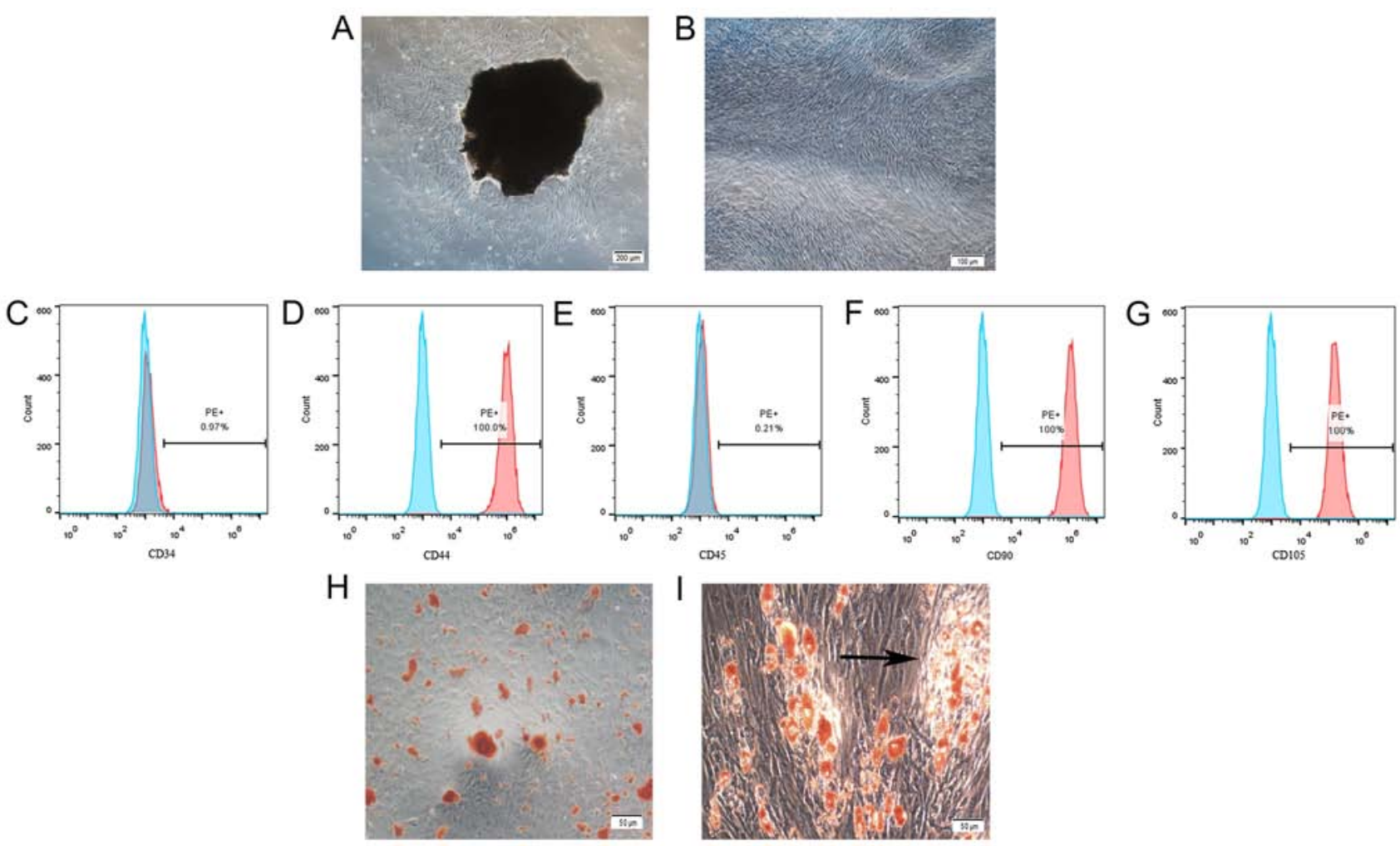

Figure 1. Identification and characteristics of hPDLSCs. Morphological characterization of hPDLSCs in (A) primary culture and (B) culture at passage 3 . A periodontal membrane fragment is present and shown in A. Flow cytometry analysis of surface markers expressed on hPDLSCs, showing that they were positive for (D) 0CD44, (F) CD90 and (G) CD105, and negative for (C) CD34 and (E) CD45. (H) Following 3 weeks of culture in osteogenic induction medium, the cells were stained with alizarin red. Mineralized nodules are shown. (I) Following 3 weeks of culture in adipogenic induction medium, the cells were stained with Oil Red O. Lipid globules are shown (black arrow). hPDLSCs, human periodontal ligament stem cells; PE, phycoerythrin.

multi-potency, and expression of cell surface markers. After seven days of incubation, hPDLSCs displayed a typical spindle-shaped morphology (Fig. 1A and B). Flow cytometry analysis showed that the hPDLSCs did not express CD34 or CD45 but expressed CD44, CD90 and CD105 (Fig. 1C-G). After three weeks of culture in osteogenic induction medium, some mineralized nodules were found in the well (Fig. 1C), and lipid droplets were also observed after four weeks of induction (Fig. 1D).

Cell viability of hPDLSCs after resveratrol and TNF- $\alpha$ treatment. Resveratrol $\left(10^{-8}\right.$ to $\left.10^{-5} \mathrm{M}\right)$ was reported to increase human bone marrow-derived mesenchymal stem cell (BMSC) growth dose-dependently (17). To investigate the effect of resveratrol and TNF- $\alpha$ on hPDLSC cell viability, cells were treated with resveratrol and/or TNF- $\alpha$ at different concentrations (resveratrol: $0.1,1$ and $10 \mu \mathrm{mol} / \mathrm{l}$; TNF- $\alpha$ : 1,5 and $10 \mathrm{ng} / \mathrm{ml})$. The CCK-8 assay was then performed on day one, three, and five. The CCK-8 assay demonstrated that resveratrol could increase hPDLSC viability. Furthermore, increases in hPDLSC viability were identified in the two high-dose groups ( 1 and $10 \mu \mathrm{mol} / \mathrm{l})$ on day 3 and $5(\mathrm{P}<0.05$; Fig. $2 \mathrm{~A})$. As expected, cell viability decreased after treatment with TNF- $\alpha$ $(10 \mathrm{ng} / \mathrm{ml})$ for one day, compared with that in the control group, and the results were similar when cells were treated with TNF- $\alpha$ for three or five days. This decrease was significant in the high-dose group at all three time points $(10 \mathrm{ng} / \mathrm{ml}$; Fig. 2B; $\mathrm{P}<0.05)$. Moreover, hPDLSC viability was increased on day one, three and five after co-treatment with $10 \mathrm{ng} / \mathrm{ml}$
TNF- $\alpha$ and $1 \mu \mathrm{mol} / 1$ resveratrol, compared with that in the control group. These results demonstrated that resveratrol could alleviate the toxicity of TNF- $\alpha$ in hPDLSCs (Fig. 2C).

Effects of different doses of resveratrol and TNF- $\alpha$ on hPDLSC osteogenesis. To examine the effect of resveratrol and TNF- $\alpha$ on osteogenesis, cells were cultured for 14 days with resveratrol $(0.1,1$ and $10 \mu \mathrm{mol} / \mathrm{l})$ or TNF- $\alpha(1,5$ and $10 \mathrm{ng} / \mathrm{ml})$. After 21 days of culture, alizarin red staining was carried out (Fig. 3B) and calcium content assays were performed. The results showed that calcium accumulation in the TNF- $\alpha$-treated groups was decreased compared to that in the control group, and that this decrease was significant in the high-dose group $(10 \mathrm{ng} / \mathrm{ml} ; \mathrm{P}<0.01)$. Furthermore, an increased number of mineralized nodules could be observed in cells treated with resveratrol (1 and $10 \mu \mathrm{mol} / \mathrm{l})$ compared with that in the control group (Fig. 3D). Cells treated with TNF- $\alpha$ had a significant decrease in the number of mineralized nodules, as observed in the high dose group compared with the control. ALP staining and activity assays were performed as a standard measurement of osteogenic activity. The results demonstrated that resveratrol did not have an effect on ALP staining or activity in hPDLSCs (Fig. 3A and C), whereas TNF- $\alpha(1 \mathrm{ng} / \mathrm{ml})$ significantly increased ALP activity. Furthermore, TNF- $\alpha(5 \mathrm{ng} / \mathrm{ml})$ did not alter ALP activity and TNF- $\alpha(10 \mathrm{ng} / \mathrm{ml})$ significantly decreased ALP activity (Fig. 3C).

Furthermore, the mRNA expression of Runx2 and $A L P$ was assessed by RT-qPCR. Levels of both markers were significantly increased after treatment with resveratrol $(1 \mu \mathrm{mol} / \mathrm{l}$; 

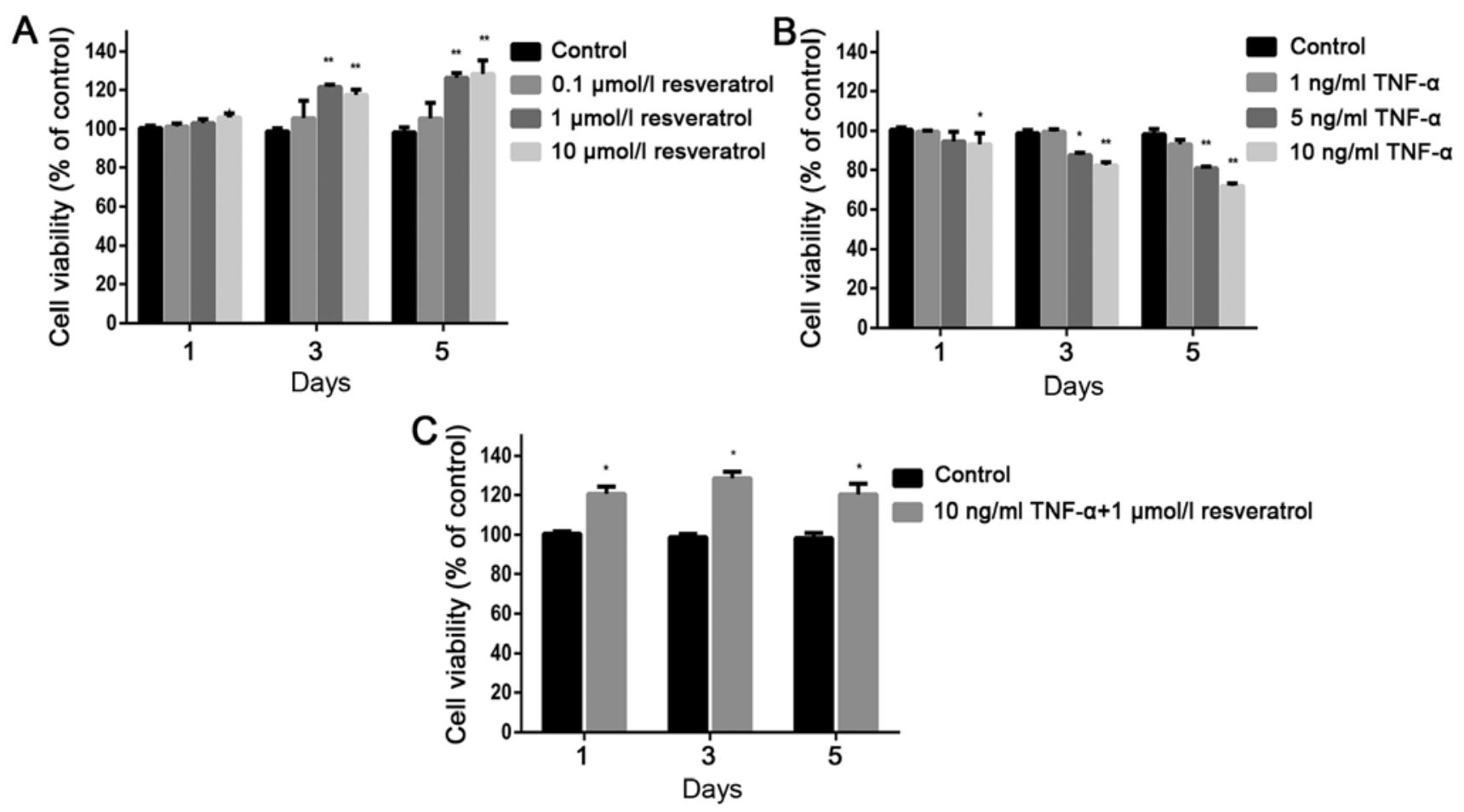

Figure 2. Cell proliferation of hPDLSCs upon resveratrol and TNF- $\alpha$ treatment. Cell proliferation of hPDLSCs treated for 1, 3 or 5 days with (A) resveratrol $(0.1,1$ and $10 \mu \mathrm{mol} / \mathrm{l})$, (B) TNF- $\alpha(1,5$, and $10 \mathrm{ng} / \mathrm{ml})$ or (C) resveratrol $(1 \mu \mathrm{mol} / \mathrm{l})$ and TNF- $\alpha(10 \mathrm{ng} / \mathrm{ml})$, measured by the Cell Counting Kit- 8 assay. All experiments were performed in triplicate. ${ }^{*} \mathrm{P}<0.05$ and ${ }^{* * *} \mathrm{P}<0.01$ vs. the control group. hPDLSCs, human periodontal ligament stem cells; TNF- $\alpha$, tumor necrosis factor- $\alpha$.

$\mathrm{P}<0.01)$ compared with that in the control group. Meanwhile, $A L P$ and Runx2 mRNA levels were significantly decreased upon treatment with TNF- $\alpha(10 \mathrm{ng} / \mathrm{ml})$ compared with those in the control groups (Fig. $3 \mathrm{E}$ and $\mathrm{F} ; \mathrm{P}<0.01$ ).

Resveratrol rescues TNF- $\alpha$ induced inhibition of osteogenesis in hPDLSCs. hPDLSCs were treated with resveratrol $(1 \mu \mathrm{mol} / \mathrm{l})$ and/or TNF- $\alpha(10 \mathrm{ng} / \mathrm{ml})$ during the three weeks of osteogenic induction. Western blot analysis showed that protein levels of ALP and Runx2 in the TNF- $\alpha$-treated group were significantly decreased compared with those in the control group (Fig. 4A-C; $\mathrm{P}<0.05$ ). Meanwhile, protein expression levels in hPDLSCs treated with both TNF- $\alpha$ and resveratrol were significantly increased compared with those in the TNF- $\alpha$-treated group (Fig. 4A-C; P<0.01). Similar results were found for mRNA expression of ALP and Runx2 using RT-qPCR (Fig. 4D and E). Taken together, these data suggested that resveratrol could rescue the TNF- $\alpha$-induced inhibition of hPDLSC osteogenesis. Moreover, it was found that resveratrol and TNF- $\alpha$ could function together to improve bone formation, by increasing ALP expression at both the mRNA and protein level, greater than resveratrol alone. Regarding Runx2 expression at the mRNA level, the combination of resveratrol and TNF- $\alpha$ had a stronger effect than resveratrol alone, but the protein levels did not reflect this. However, these changes are not statistically significant.

Resveratrol attenuates hPDLSC secretion of inflammatory cytokines induced by $T N F-\alpha$. To assess cytokine secretion in response to resveratrol $(1 \mu \mathrm{mol} / \mathrm{l})$ and TNF- $\alpha(10 \mathrm{ng} / \mathrm{ml})$, hPDLSCs were treated with either TNF- $\alpha$ alone or with both TNF- $\alpha$ and resveratrol for $24 \mathrm{~h}$. Data from RT-qPCR showed that the mRNA expression of $I L-6$ and $I L-8$ in the TNF- $\alpha$-treated group was significantly increased compared with that in the control group $(\mathrm{P}<0.01)$. However, co-treatment did not change mRNA expression of $I L-6$ and $I L-8$ compared with that in the control group (Fig. 4F). These results indicated that resveratrol attenuates the inflammatory effects of TNF- $\alpha$.

Resveratrol rescues the TNF- $\alpha$-induced inhibition of osteogenesis via the ERK1/2 pathway. The MAPK pathway, comprised of serine/threonine protein kinases, plays an important role in regulating cell migration, proliferation and differentiation $(28,29)$. To determine whether the ERK1/2 signaling pathway is involved in the protective effects of resveratrol on hPDLSC osteogenic differentiation, the phosphorylation and total levels of ERK in treated hPDLSCs were measured. Western blot analysis showed that p-ERK gradually increased by $5 \mathrm{~min}$ and peaked at $15 \mathrm{~min}$, after which it returned to basal levels (Fig. 5A and B). Furthermore, PD98059 (10 mmol/l) was added to the serum-free cell culture media $1 \mathrm{~h}$ prior to application of resveratrol to inhibit ERK signaling. As expected, the protein expression of p-ERK was significantly inhibited by PD98059, compared with that in the control group (Fig. 5C and $\mathrm{D} ; \mathrm{P}<0.01$ ). Results also showed that the mRNA and protein expression levels of IL-6 and IL-8 increased when PD98059 was added to the co-treated group, compared with those in the co-treated group alone (Fig. 5E-G). Data indicated that the anti-inflammatory effects of resveratrol decreased after blocking the ERK1/2 signaling pathway. Thus, these results together indicated that resveratrol can activate the ERK1/2 signaling pathway to attenuate the secretion of inflammatory 
A

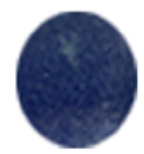

Control

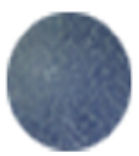

TNF- $\alpha$

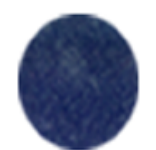

Resveratrol
B

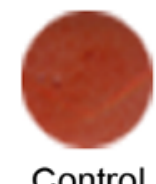

Control

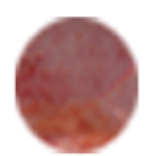

TNF- $\alpha$

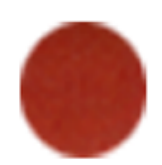

Resveratrol

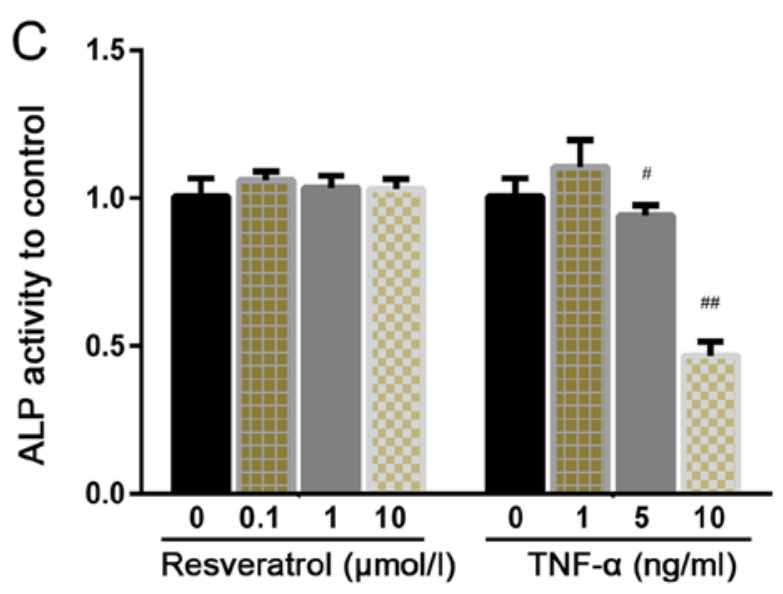

D
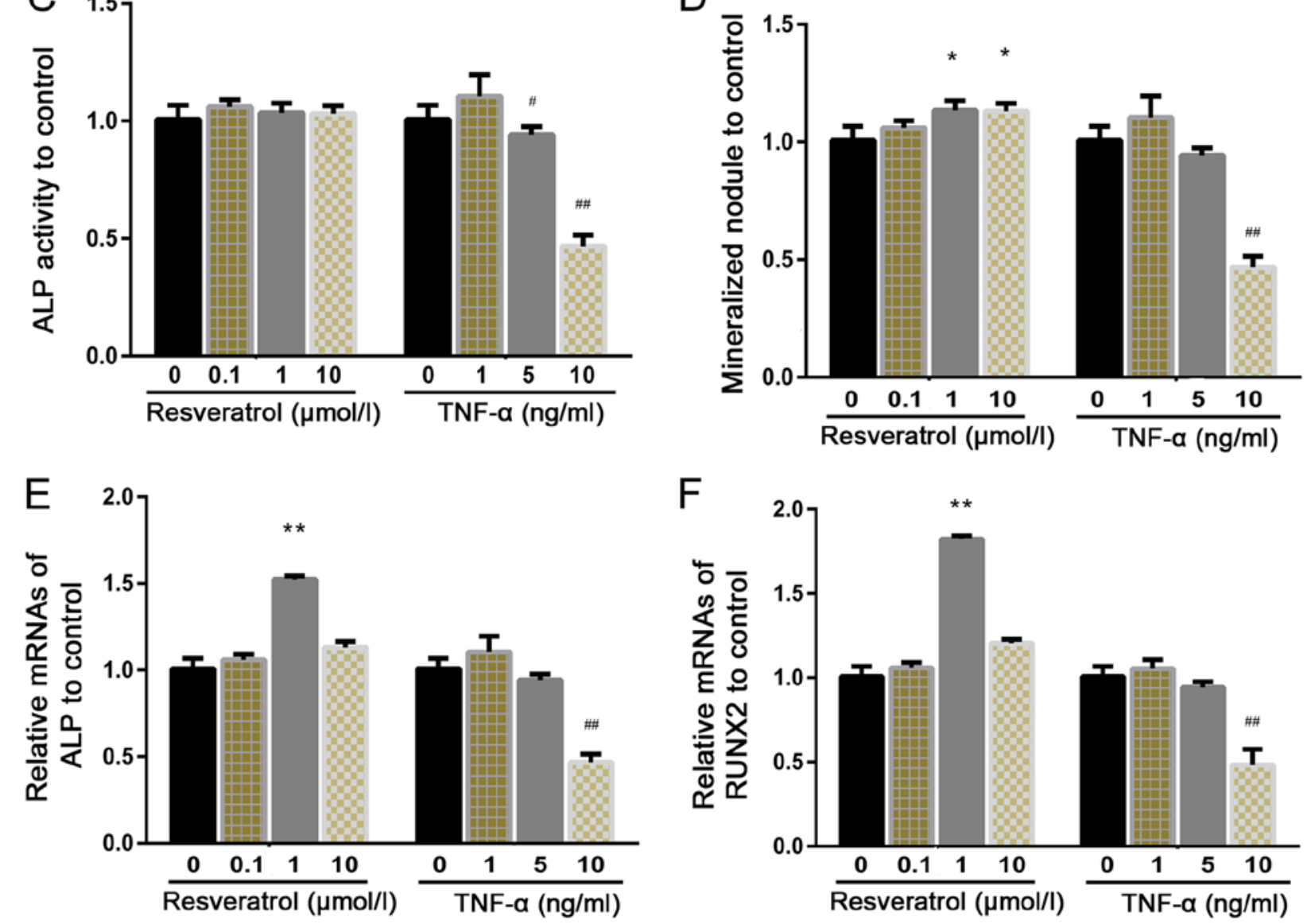

Figure 3. Effects of resveratrol and TNF- $\alpha$ at different doses on osteogenesis of hPDLSCs. (A) Representative image of hPDLSCs cultured for 14 days in osteogenic medium, osteogenic medium + TNF- $\alpha 10 \mathrm{ng} / \mathrm{ml}$ or osteogenic medium + resveratrol $1 \mu \mathrm{mol} / 1$ were used for ALP. Magnification, x10. (B) Representative image of hPDLSCs were cultured for 21 days in osteogenic medium, osteogenic medium + TNF- $\alpha 10 \mathrm{ng} / \mathrm{ml}$ or osteogenic medium + resveratrol $1 \mu$ mol/l for alizarin red staining. Magnification, x10). (C) Relative ALP activity. (D) Mineralized nodule analysis. Relative mRNA expression of (E) $A L P$ and (F) Runx2. ${ }^{*} \mathrm{P}<0.05$ and ${ }^{* *} \mathrm{P}<0.01$ vs. $0 \mu \mathrm{mol} / 1$ resveratrol group. ${ }^{\#} \mathrm{P}<0.05$ and ${ }^{\# /} \mathrm{P}<0.01$ vs. $10 \mathrm{ng} / \mathrm{ml}$ TNF- $\alpha$ group. TNF- $\alpha$, tumor necrosis factor- $\alpha$; hPDLSCs, human periodontal ligament stem cells; ALP, alkaline phosphatase staining; Runx2, runt-related transcription factor 2.

cytokines by hPDLSCs upon exposure to TNF- $\alpha$, this in turn enhances osteogenic differentiation.

\section{Discussion}

Plaque bacteria are the initiating factor of periodontitis, and the host reaction stimulated by these microorganisms is the main cause of periodontal tissue destruction (30). The development of tissue engineering provides new approaches for dental tissue regeneration (31). In 2004, Seo et al (3) successfully isolated and cultured stem cells from periodontal ligaments of the third molar. PDLSCs express mesenchymal stem-cell markers, and can differentiate into cementoblast-like cells, adipocytes and collagen-forming cells under defined culture conditions (3). Moreover, PDLSCs also have the capacity to generate a cementum/PDL-like structures when transplanted into immunocompromised rodents (3). This highlighted that this stem cells could be used for research on periodontal tissue repair.

In the present study, a comprehensive assessment of the effect of TNF- $\alpha$ and resveratrol on the proliferation and osteogenic differentiation of hPDLSCs was carried out. Results showed that TNF- $\alpha$ could significantly decrease hPDLSC viability and osteogenic differentiation at a high concentration $(10 \mathrm{ng} / \mathrm{ml})$, whereas co-treatment with TNF- $\alpha$ and resveratrol rescued such TNF- $\alpha$-induced inhibitory effects.

TNF- $\alpha$ is a $17-k D a$ cytokine produced by mononuclear macrophages and other immune cells (32). It is currently recognized as an important endogenous inducible pro-inflammatory cytokine and a critical inflammatory mediator of responses to infectious diseases (33). Additionally, TNF- $\alpha$ actively participates in osteoclastogenesis and tissue destruction observed in periodontal diseases (34). Gilbert et al (35) reported that TNF- $\alpha$ is a potent inhibitor of osteoblast differentiation in a normal 
A

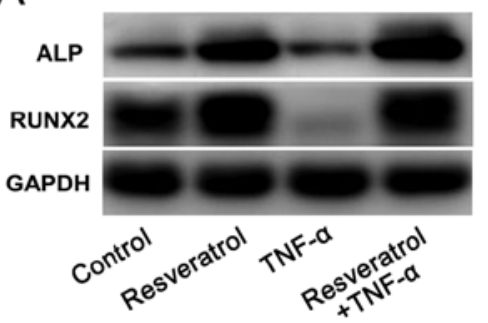

B

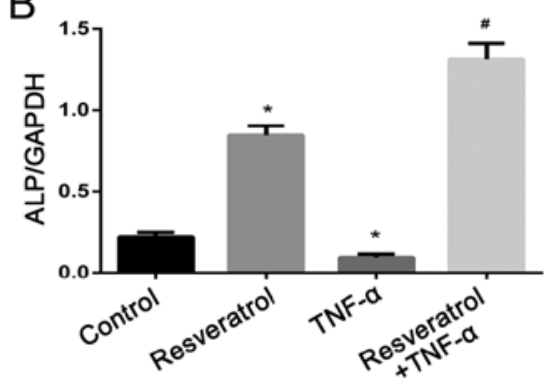

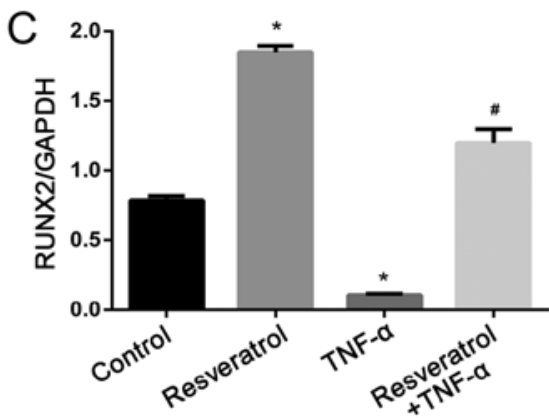

$\mathrm{F}$
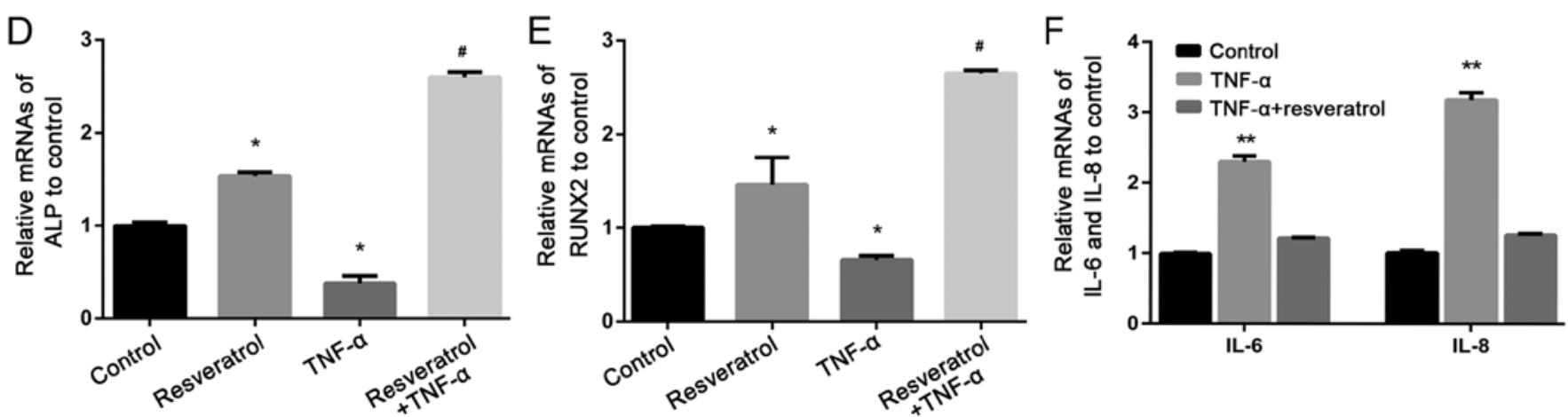

Figure 4. Resveratrol rescues TNF- $\alpha$-induced inhibition of osteogenesis in hPDLSCs and attenuates the secretion of inflammatory cytokines induced by TNF- $\alpha$. hPDLSCs were treated with TNF- $\alpha(10 \mathrm{ng} / \mathrm{ml})$, resveratrol $(1 \mu \mathrm{mol} / \mathrm{l})$ or both (A) Western blot analysis of ALP and Runx 2 levels in hPDLSCs cultured for 21 days. Semi-quantitative analysis of (B) ALP and (C) Runx2 protein levels in hPDLSCs cultured for 21 days. Relative expression of (D) ALP and (E) Runx2 mRNA. (F) Relative expression of $I L-6$ and $I L-8$ mRNA in hPDLSCs cultured for 24 h. ${ }^{*} \mathrm{P}<0.05$ and ${ }^{* *} \mathrm{P}<0.01$ vs. the control group; ${ }^{\#} \mathrm{P}<0.05$ vs. the TNF- $\alpha$-treated group. TNF- $\alpha$, tumor necrosis factor- $\alpha$; hPDLSCs, human periodontal ligament stem cells; ALP, alkaline phosphatase; Runx 2 , runt-related transcription factor 2; IL, interleukin.

osteoblast-like cell line (MC3T3-E1 cells). Lacey et al (36) reported that TNF- $\alpha$ inhibits ALP activity, as well as ALP and Runx 2 gene expression during the osteoblastic differentiation of murine BMSCs.

In addition, Feng et al (37) found that $10 \mathrm{ng} / \mathrm{ml}$ of TNF- $\alpha$ could promote mineralization and mineralization-related gene expression via the NF- $\kappa \mathrm{B}$ signaling pathway in dental pulp stem cells. Furthermore, in a murine mesenchymal stem cell line (ST2 cells), levels of Runx2, osteocalcin and ALP were found to be upregulated in cell cultures treated with TNF- $\alpha$ at lower concentrations ( 0.01 and $0.1 \mathrm{ng} / \mathrm{ml})$, but were downregulated in cell cultures treated with TNF- $\alpha$ at higher concentrations of 10 and $100 \mathrm{ng} / \mathrm{ml}$. Long-term treatment with TNF- $\alpha$ at all concentrations induced inhibitory effects on mineral nodule formation (38). However, after treatment with TNF- $\alpha$ at $1 \mathrm{ng} / \mathrm{ml}$, human primary osteoblasts were able to promote the osteogenesis of adipose tissue-derived MSCs (39). The exact reason for these contradictory results is unknown, but one possibility is the different stem cell types used for in vitro studies.

To the best of our knowledge, the effect of TNF- $\alpha$ on the osteogenic differentiation of periodontal ligament stem cells has not been previously reported. In the present study, the effect of different TNF- $\alpha$ concentrations on the proliferation and osteogenic differentiation of hPDLSCs was assessed. Data showed that TNF- $\alpha(10 \mathrm{ng} / \mathrm{ml})$ could significantly inhibit both processes in hPDLSCs. Furthermore, the present study found that co-treatment of hPDLSCs with resveratrol and TNF- $\alpha$ could prevent this inhibitory effect. Similar protective effects of resveratrol in response to TNF- $\alpha$ have been were reported in cardiac stem cells (40), fibroblasts (41) and endothelial cells (42).

Previous studies have also shown that resveratrol possesses potent bone-protective properties. Specifically, Song et al (43) reported that resveratrol rescues the inhibitory effects of cyclosporin A on proliferation and osteoblastic differentiation in murine BMSCs. Further to this, Boissy et al (44) reported that resveratrol can enhance the mRNA expression of osteocalcin and osteopontin, two osteoblastic markers, in immortalized osteoblast-like cells. Other studies have also confirmed these findings (16-18). These in vitro findings have been further supported by an in vivo study. Durbin et al (45) showed that resveratrol consumption could prevent bone loss in the hind limbs of rats. Moreover, three months of treatment with resveratrol was found to rescue ovariectomy-induced bone loss in rats $(46,47)$. In the present study, the protein expression of ALP and Runx2 were measured to assess the effect of resveratrol on hPDLSCs. Expression of both markers at the protein level were increased by resveratrol, with the relative expression of ALP and Runx2 genes following a similar trend. These results are consistent with a study on ST2 cells, which showed that resveratrol could significantly enhance the mRNA expression of Runx2 (48). Although there is evidence supporting the enhancing effects of resveratrol on the osteogenic differentiation of hPDLSCs, the underlying mechanism was previously unclear.

Tseng et al (18) reported a novel mechanism associated with resveratrol in enhancing the osteogenesis of human MSCs by upregulating Runx2 gene expression via the SIRT1/FOXO3A axis. Resveratrol can also promote the 
A
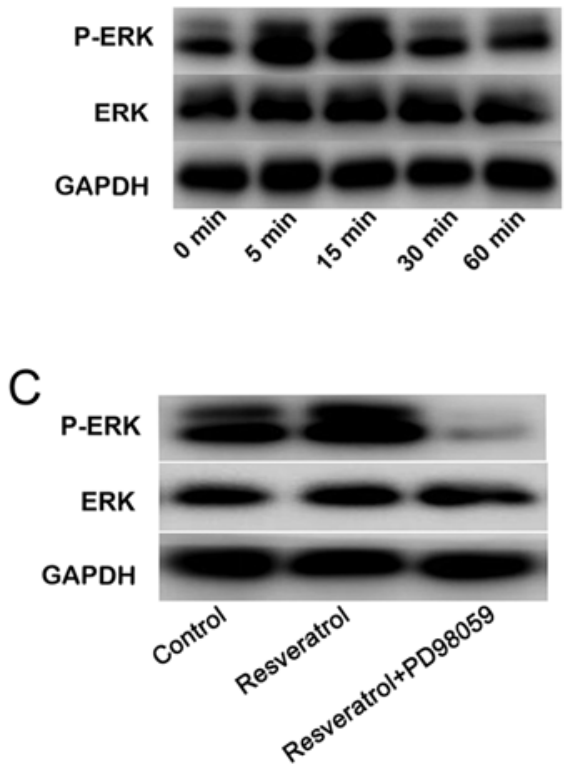

B

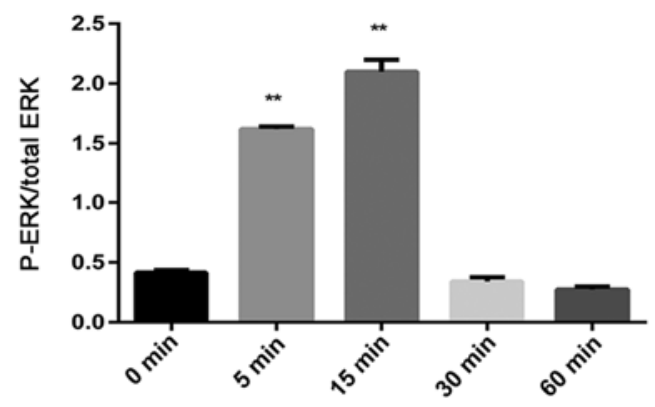

$\mathrm{D}$

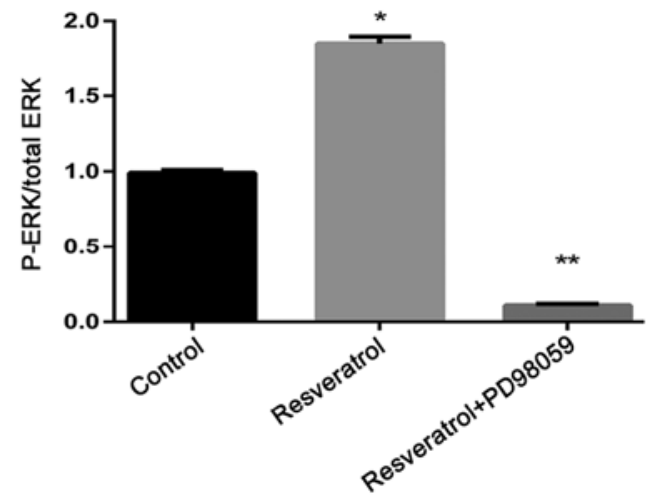

E

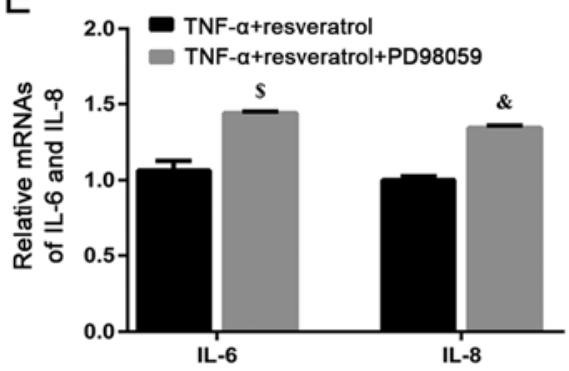

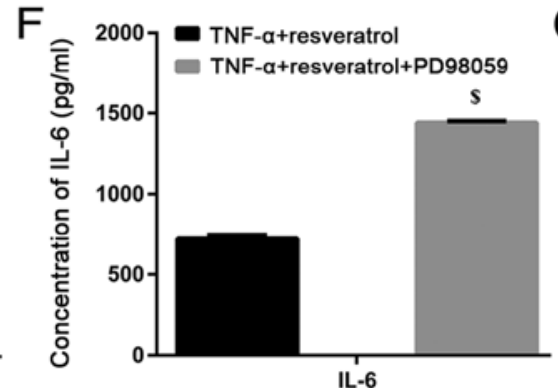
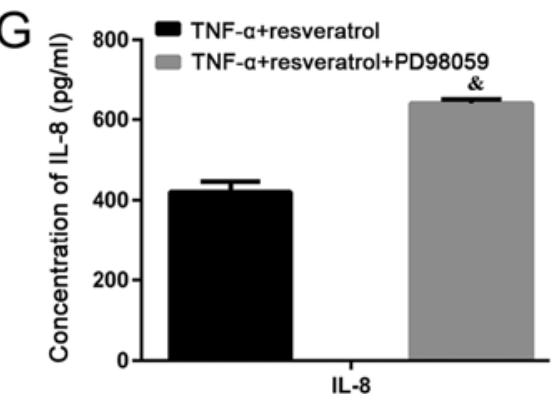

Figure 5. ERK1/2 pathway is required for the inhibitory effects of resveratrol on TNF- $\alpha$-induced inflammation and enhanced osteogenesis in hPDLSCs. Levels of p-ERK/total ERK were (A) determined by western blot analysis and (B) quantified in hPDLSCs treated with resveratrol (1 $\mu$ mol/l) for the indicated times $(0,5,15,30$ and $60 \mathrm{~min})$. Levels of p-ERK/total ERK were (C) determined by western blot analysis and (D) quantified in hPDLSCs treated with resveratrol ( $1 \mu \mathrm{mol} / 1)$ or resveratrol $(1 \mu \mathrm{mol} / \mathrm{l})$ plus PD98059 $\left(10^{-5} \mathrm{~mol} / 1\right)$. hPDLSCs treated with TNF- $\alpha(10 \mathrm{ng} / \mathrm{ml})$ and resveratrol $(1 \mu \mathrm{mol} / \mathrm{l})$ or TNF- $\alpha$ (10 ng/ml), resveratrol $(1 \mu \mathrm{mol} / \mathrm{l})$ and PD98059 $\left(10^{-5} \mathrm{~mol} / \mathrm{l}\right)$, then cultured for $24 \mathrm{~h}$. (E) Relative mRNA expression levels of IL-6 and IL-8. Protein concentrations of (F) IL-6 and (G) IL-8. ${ }^{*} \mathrm{P}<0.05$ and ${ }^{* *} \mathrm{P}<0.01$ vs. control. ${ }^{\$} \mathrm{P}<0.05$ vs. IL-6 (TNF- $\alpha+$ resveratrol) group. ${ }^{\&} \mathrm{P}<0.05$ vs. IL-8 (TNF- $\alpha+$ resveratrol) group. TNF- $\alpha$, tumor necrosis factor- $\alpha$; hPDLSCs, human periodontal ligament stem cells; p, phosphorylated; IL, interleukin.

osteoblastic differentiation of multipotent mesenchymal cells via the canonical Wnt signaling pathway (48). Further to this, via the ERK/MAPK/nitric oxide synthase (NOS)/cyclic GMP axis, resveratrol was found to promote osteoblastic differentiation and osteogenic gene expression in human BMSC cultures (43). To explore the molecular mechanism underlying the effects of resveratrol on hPDLSCs, the expression and phosphorylation levels of ERK1/2 were evaluated. The present study demonstrated that resveratrol could rapidly activate ERK1/2 signaling within $5 \mathrm{~min}$. Moreover, results showed that this was blocked on addition of PD98059 $\left(10^{-5} \mathrm{~mol} / \mathrm{l}\right) 1 \mathrm{~h}$ prior to resveratrol application. A previous study found that resveratrol stimulates osteoblastic differentiation and osteogenic gene expression in human MSCs via ERK-dependent ERK1/2 activation (13). Therefore, it is speculated that resveratrol can similarly enhance the osteogenic differentiation of hPDLSCs by activating the ERK1/2 pathway.

The present study was the first to find that Resveratrol can attenuate the secretion of inflammatory cytokines mediated by TNF- $\alpha$. Upon further exploring the underlying mechanisms, it was found that the mRNA expression of $I L-6$ and $I L-8$ significantly increased after addition of PD98059 to the co-treated group (Fig. 5E). This result is consistent with the protein levels of secreted IL- 6 and IL-8, measured by ELISA (Fig. 5F and G). These results further indicate that the anti-inflammatory effect of resveratrol might occur via activation of the ERK1/2 signaling pathway. Previous studies reported that resveratrol attenuates inflammation in experimental caustic esophageal burns (49), acute small intestinal inflammation (50), and tissue damage in a dextran sulfate sodium-induced colitis rat model (51). Resveratrol also attenuates inflammation by inhibiting the activity of NF- $\kappa \mathrm{B}$ and activating protein 1 simultaneously. The present study provides a new molecular mechanism by which resveratrol exerts anti-inflammatory activity, specifically, by activating the ERK1/2 pathway, improving the inflammatory microenvironment, and enhancing the osteogenic differentiation of hPDLSCs.

In conclusion, the present study is the first to demonstrate that resveratrol not only enhances the osteogenesis of hPDLSCs by activating the ERK1/2 pathway, but also exerts anti-inflammatory 
effects by activating this pathway. Ultimately,resveratroldecreases the TNF- $\alpha$-mediated secretion of inflammatory cytokines and enhances osteogenesis in hPDLSCs. Therefore, resveratrol may be a good candidate for an anti-inflammatory agent that can induce bone remodeling in response to an inflammatory microenvironment. However, further in vivo experiments are required to evaluate the efficacy and safety of its clinical application for the treatment of periodontitis.

\section{Acknowledgements}

The authors would like to thank the Director of Shandong Provincial Key Laboratory of Oral Tissue Regeneration for providing technical support.

\section{Funding}

This work was supported by a grant from the National Natural Science Foundation of China (grant. no. 81371180).

\section{Availability of data and materials}

The datasets used and/or analyzed during the current study are available from the corresponding author on reasonable request.

\section{Authors' contributions}

JZ designed the experiments. JY and XW performed the experiments. JZ, XW, DM, HG and DZ analyzed the data. JY wrote the manuscript. All authors read and approved the final manuscript.

\section{Ethics approval and consent to participate}

This study was approved by the Medical Ethical Committee of the School of Stomatology, Shandong University. Each participant and the legal guardian of all children provided written informed consent in accordance with The Declaration of Helsinki.

\section{Patient consent for publication}

Not applicable.

\section{Competing interests}

The authors declare that they have no competing interests.

\section{References}

1. Chen FM, Zhang J, Zhang M, An Y, Chen F and Wu ZF: A review on endogenous regenerative technology in periodontal regenerative medicine. Biomaterials 31: 7892-7927, 2010.

2. Han J, Menicanin D, Gronthos S and Bartold PM: Stem cells, tissue engineering and periodontal regeneration. Aust Dent J 59 (Suppl 1): S117-S130, 2014.

3. Seo BM, Miura M, Gronthos S, Bartold PM, Batouli S, Brahim J, Young M, Robey PG, Wang CY and Shi S: Investigation of multipotent postnatal stem cells from human periodontal ligament. Lancet 364: 149-155, 2004.

4. Lindsay R and Tohme JF: Estrogen treatment of patients with established postmenopausal osteoporosis. Obstet Gynecol 76: 290-295, 1990.
5. Zaidi M: Skeletal remodeling in health and disease. Nat Med 13: 791-801, 2007.

6. Falahati-Nini A, Riggs BL, Atkinson EJ, O'Fallon WM, Eastell R and Khosla S: Relative contributions of testosterone and estrogen in regulating bone resorption and formation in normal elderly men. J Clin Invest 106: 1553-1560, 2000.

7. Lampe $J$ and Messina M: Are phytoestrogens nature's cure for what ails us? A look at the research. Interview by Nancy I. Hahn. J Am Diet Assoc 98: 974-976, 1998.

8. Jang M, Cai L, Udeani GO, Slowing KV, Thomas CF, Beecher CW, Fong HH, Farnsworth NR, Kinghorn AD, Mehta RG, et al: Cancer chemopreventive activity of resveratrol, a natural product derived from grapes. Science 275: 218-210, 1997.

9. Gehm BD, McAndrews JM, Chien PY and Jameson JL: Resveratrol, a polyphenolic compound found in grapes and wine, is an agonist for the estrogen receptor. Proc Natl Acad Sci USA 94: 14138-14143, 1997.

10. Hao XD, Chang J, Qin BY, Zhong C, Chu ZB, Huang J, Zhou WJ and Sun X: Synthesis, estrogenic activity, and anti-osteoporosis effects in ovariectomized rats of resveratrol oligomer derivatives. Eur J Med Chem 102: 26-38, 2015.

11. Savouret JF and Quesne M: Resveratrol and cancer: A review. Biomed Pharmacother 56: 84-87, 2002.

12. Cao Z and Li Y: Potent induction of cellular antioxidants and phase 2 enzymes by resveratrol in cardiomyocytes: Protection against oxidative and electrophilic injury. Eur J Pharmacol 489: $39-48,2004$.

13. Gómez-Zorita S, Fernández-Quintela A, Lasa A, Hijona E, Bujanda L and Portillo MP: Effects of resveratrol on obesity-related inflammation markers in adipose tissue of genetically obese rats. Nutrition 29: 1374-1380, 2013.

14. Ornstrup MJ, Harsløf T, Kjær TN, Langdahl BL and Pedersen SB: Resveratrol increases bone mineral density and bone alkaline phosphatase in obese men: A randomized placebo-controlled trial. J Clin Endocrinol Metab 99: 4720-4729, 2014.

15. Bo S, Gambino R, Ponzo V, Cioffi I, Goitre I, Evangelista A, Ciccone G, Cassader M and Procopio M: Effects of resveratrol on bone health in type 2 diabetic patients. A double-blind randomized-controlled trial. Nutr Diabetes 8: 51, 2018.

16. Mizutani K, Ikeda K, Kawai Y and Yamori Y: Resveratrol stimulates the proliferation and differentiation of osteoblastic MC3T3-E1 cells. Biochem Biophys Res Commun 253: 859-863, 1998.

17. Dai Z, Li Y, Quarles LD, Song T, Pan W, Zhou H and Xiao Z: Resveratrol enhances proliferation and osteoblastic differentiation in human mesenchymal stem cells via ER-dependent ERK1/2 activation. Phytomedicine 14: 806-814, 2007.

18. Tseng PC, Hou SM, Chen RJ, Peng HW, Hsieh CF, Kuo ML and Yen ML: Resveratrol promotes osteogenesis of human mesenchymal stem cells by upregulating Runx 2 gene expression via the SIRT1/FOXO3A axis. J Bone Miner Res 26: 2552-2563, 2011.

19. Kwan Tat S, Padrines M, Théoleyre S, Heymann D and Fortun Y: IL-6, RANKL, TNF-alpha/IL-1: Interrelations in bone resorption pathophysiology. Cytokine Growth Factor Rev 15: 49-60, 2004.

20. Brennan FM, Maini RN and Feldmann M: TNF alpha-a pivotal role in rheumatoid arthritis? Br J Rheumatol 31: 293-298, 1992.

21. Bartold PM, Cantley MD and Haynes DR: Mechanisms and control of pathologic bone loss in periodontitis. Periodontol 2000 53: 55-69, 2010.

22. Digirolamo CM, Stokes D, Colter D, Phinney DG, Class R and Prockop DJ: Propagation and senescence of human marrow stromal cells in culture: A simple colony-forming assay identifies samples with the greatest potential to propagate and differentiate. Br J Haematol 107: 275-281, 1999.

23. Du L, Yang P and Ge S: Stromal cell-derived factor-1 significantly induces proliferation, migration, and collagen type I expression in a human periodontal ligament stem cell subpopulation. J Periodontol 83: 379-388, 2012.

24. Shigetani Y, Ohkura N, Yoshiba K, Ohshima H, Hosoya A, Yoshiba A and Okiji T: GaAlAs laser-induced pulp mineralization involves dentin matrix protein 1 and osteopontin expression. Oral Dis 22: 399-405, 2016.

25. Livak KJ and Schmittgen TD: Analysis of relative gene expression data using real-time quantitative PCR and the 2(-Delta Delta C(T)) method. Methods 25: 402-408, 2001.

26. Simmons CA, Matlis S, Thornton AJ, Chen S, Wang CY and Mooney DJ: Cyclic strain enhances matrix mineralization by adult human mesenchymal stem cells via the extracellular signal-regulated kinase (ERK1/2) signaling pathway. J Biomech 36: 1087-1096, 2003 
27. Alessi DR, Cuenda A, Cohen P, Dudley DT and Saltiel AR: PD 098059 is a specific inhibitor of the activation of mitogen-activated protein kinase kinase in vitro and in vivo. J Biol Chem 270: 27489-27494, 1995

28. Gehart H, Kumpf S, Ittner A and Ricci R: MAPK signalling in cellular metabolism: Stress or wellness? EMBO Rep 11: 834-840, 2010.

29. Roy SK, Srivastava RK and Shankar S: Inhibition of PI3K/AKT and MAPK/ERK pathways causes activation of FOXO transcription factor, leading to cell cycle arrest and apoptosis in pancreatic cancer. J Mol Signal 5: 10, 2010.

30. Page RC: The pathobiology of periodontal diseases may affect systemic diseases: Inversion of a paradigm. Ann Periodontol 3: 108-120, 1998

31. Galler KM and D'Souza RN: Tissue engineering approaches for regenerative dentistry. Regen Med 6: 111-124, 2011.

32. Beutler B, Greenwald D, Hulmes JD, Chang M, Pan YC, Mathison J, Ulevitch R and Cerami A: Identity of tumour necrosis factor and the macrophage-secreted factor cachectin. Nature 316: 552-554, 1985.

33. Suffredini AF, Reda D, Banks SM, Tropea M, Agosti JM and Miller R: Effects of recombinant dimeric TNF receptor on human inflammatory responses following intravenous endotoxin administration. J Immunol 155: 5038-5045, 1995.

34. Brunetti G, Colucci S, Pignataro P, Coricciati M, Mori G, Cirulli N, Zallone A, Grassi FR and Grano M: T cells support osteoclastogenesis in an in vitro model derived from human periodontitis patients. J Periodontol 76: 1675-1680, 2005

35. Gilbert L, He X, Farmer P, Boden S, Kozlowski M, Rubin J and Nanes MS: Inhibition of osteoblast differentiation by tumor necrosis factor-alpha. Endocrinology 141: 3956-3964, 2000.

36. Lacey DC, Simmons PJ, Graves SE and Hamilton JA Proinflammatory cytokines inhibit osteogenic differentiation from stem cells: Implications for bone repair during inflammation. Osteoarthritis Cartilage 17: 735-742, 2009.

37. Feng X, Feng G, Xing J, Shen B, Li L, Tan W, Xu Y, Liu S, Liu H, Jiang J, et al: TNF- $\alpha$ triggers osteogenic differentiation of human dental pulp stem cells via the NF- $\kappa \mathrm{B}$ signalling pathway. Cell Biol Int 37: 1267-1275, 2013.

38. Huang H, Zhao N, Xu X, Xu Y, Li S, Zhang J and Yang P Dose-specific effects of tumor necrosis factor alpha on osteogenic differentiation of mesenchymal stem cells. Cell Prolif 44: 420-427, 2011

39. Lu Z, Wang G, Dunstan CR and Zreiqat H: Short-term exposure to tumor necrosis factor-alpha enables human osteoblast to direct adipose tissue-derived mesenchymal stem cells into osteogenic differentiation. Stem Cells Dev 21: 2420-2429, 2012.

40. Gorbunov N, Petrovski G, Gurusamy N, Ray D, Kim DH and Das DK: Regeneration of infarcted myocardium with resveratrol-modified cardiac stem cells. J Cell Mol Med 16: 174-184, 2012
41. Zhu X, Liu Q, Wang M, Liang M, Yang X, Xu X, Zou H and Qiu J: Activation of Sirt1 by resveratrol inhibits TNF- $\alpha$ induced inflammation in fibroblasts. PLoS One 6: e27081, 2011.

42. Bertelli AA, Baccalini R, Battaglia E, Falchi M and Ferrero ME: Resveratrol inhibits TNF alpha-induced endothelial cell activation. Therapie 56: 613-616, 2001.

43. Song LH, Pan W, Yu YH, Quarles LD, Zhou HH and Xiao ZS: Resveratrol prevents CsA inhibition of proliferation and osteoblastic differentiation of mouse bone marrow-derived mesenchymal stem cells through an ER/NO/cGMP pathway. Toxicol In Vitro 20: 915-922, 2006.

44. Boissy P, Andersen TL, Abdallah BM, Kassem M, Plesner T and Delaissé JM: Resveratrol inhibits myeloma cell growth, prevents osteoclast formation, and promotes osteoblast differentiation. Cancer Res 65: 9943-9952, 2005

45. Durbin SM, Jackson JR, Ryan MJ, Gigliotti JC, Alway SE and Tou JC: Resveratrol supplementation preserves long bone mass, microstructure, and strength in hindlimb-suspended old male rats. J Bone Miner Metab 32: 38-47, 2014

46. Liu ZP, Li WX, Yu B, Huang J, Sun J, Huo JS and Liu CX: Effects of trans-resveratrol from Polygonum cuspidatum on bone loss using the ovariectomized rat model. J Med Food 8: 14-19, 2005.

47. Zhao H, Li X, Li N, Liu T, Liu J, Li Z, Xiao H and Li J: Long-term resveratrol treatment prevents ovariectomy-induced osteopenia in rats without hyperplastic effects on the uterus. Br J Nutr 111: 836-846, 2014.

48. Zhou H, Shang L, Li X, Zhang X, Gao G, Guo C, Chen B, Liu Q, Gong Y and Shao C: Resveratrol augments the canonical Wnt signaling pathway in promoting osteoblastic differentiation of multipotent mesenchymal cells. Exp Cell Res 315: 2953-2962, 2009.

49. Uguralp S, Irsi C, Aksoy T, Karabulut AB, Kirimlioglu H and Mizrak B: Resveratrol attenuates inflammation and stricture formation in experimental caustic esophageal burns. Pediatr Surg Int 24: 425-430, 2008.

50. Bereswill S, Muñoz M, Fischer A, Plickert R, Haag LM, Otto B Kühl AA, Loddenkemper C, Göbel UB and Heimesaat MM: Anti-inflammatory effects of resveratrol, curcumin and simvastatin in acute small intestinal inflammation. PLoS One 5: e15099, 2010.

51. Larrosa M, Yañéz-Gascón MJ, Selma MV, González-Sarrías A, Toti S, Cerón JJ, Tomás-Barberán F, Dolara P and Espín JC: Effect of a low dose of dietary resveratrol on colon microbiota, inflammation and tissue damage in a DSS-induced colitis rat model. J Agric Food Chem 57: 2211-2220, 2009.

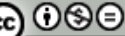

This work is licensed under a Creative Commons Attribution-NonCommercial-NoDerivatives 4.0 International (CC BY-NC-ND 4.0) License. 